\title{
Industrial Ecological Efficiency of Cities in the Yellow River Basin in the Background of China's Economic Transformation: Spatial-Temporal Characteristics and Influencing Factors
}

\section{Chengzhen Song}

Shandong Normal University

\section{Guanwen Yin}

Shandong Normal University

Zhilin Lu

Shandong Normal University

Yanbin Chen ( $\square$ ychen@sdnu.edu.cn )

Shandong Normal University https://orcid.org/0000-0001-6259-595X

\section{Research Article}

Keywords: Industrial ecological efficiency, Super-efficiency DEA model, Economic transformation, Yellow River Basin

Posted Date: June 25th, 2021

DOI: https://doi.org/10.21203/rs.3.rs-544454/v1

License: (c) (1) This work is licensed under a Creative Commons Attribution 4.0 International License. Read Full License

Version of Record: A version of this preprint was published at Environmental Science and Pollution Research on August 17th, 2021. See the published version at https://doi.org/10.1007/s11356-021-159642. 
Industrial ecological efficiency of cities in the Yellow River Basin in the background of China's economic transformation: spatial-temporal characteristics and influencing factors

\author{
Chengzhen Song \\ Postgraduate student \\ College of Geography and Environment \\ Shandong Normal University \\ Jinan 250358, China \\ Email: songchengzhensdnu@163.com
}

Guanwen Yin

Associate professor

College of Geography and Environment

Shandong Normal University

Jinan 250358, China

Email: yingw@sdnu.edu.cn

Zhilin Lu

Postgraduate student

College of Geography and Environment

Shandong Normal University

Jinan 250358, China

Email: 496260672@qq.com

Yanbin Chen

Lecturer

College of Geography and Environment

Shandong Normal University

Jinan 250358, China

Email: ychen@sdnu.edu.cn

(Corresponding author) 


\section{Industrial ecological efficiency of cities in the Yellow River Basin} in the background of China's economic transformation: spatialtemporal characteristics and influencing factors

Abstract: At present, China's economic development has entered a "new normal." Exploring Industrial ecological efficiency (IEE) in the background of economic transformation is of great significance to promote China's industrial transformation and upgrading and achieving high-quality economic development. Based on the Super-Efficiency DEA model, this study evaluated the IEE of cities in the Yellow River Basin from 2008 to 2017. Exploratory spatial data analysis methods were used to explore the spatial-temporal evolutionary characteristics, and a panel regression model was established to explore the influencing factors of IEE. The research results showed that: The IEE in the Yellow River Basin exhibited an elongated S-shaped evolutionary trend from 2008 to 2017, and the mean IEE of cities presented a trend whereby Yellow River Basin's regions could be ranked in the following order: lower reaches > middle reaches $>$ upper reaches. There was significant spatial autocorrelation of the IEE in the Yellow River Basin, and the hot and cold spots showed an obvious "spatial clubs" phenomenon. The results of panel regression show that the influence factors of IEE in the Yellow River Basin showed spatial heterogeneity in their effect.

Keywords: Industrial ecological efficiency; Super-efficiency DEA model; Economic transformation; Yellow River Basin

\section{Introduction}

Since China's economic reform and opening up, it has relied on the traditional extensive industrial development pattern of "high resource input, high energy consumption, and high pollution emissions," enabling the economy to achieve high-speed growth in a short period of time (Wang et al. 2016). However, 
the traditional industrial development model has also led to problems such as excessive resource consumption, serious environmental pollution, and low production efficiency (Yu et al. 2015, Yu et al. 2018). At present, the Chinese economy has shifted from a high-speed growth stage to a high-quality development stage. Achieving the coordinated development of industrial economic growth, resource conservation, and environmental protection has become the only way to promote China's ecological civilization construction and high-quality economic development.

In the early 1990s, Schaltegger andSturm (1990) proposed the concept of eco-efficiency, or the ratio between the increase in economic output and the increase in environmental impact, to measure the environmental performance of economic development. The basic idea of eco-efficiency is to create greater economic benefits with lower resource consumption and environmental cost. IEE not only reflects the eco-efficiency of economic growth, but it also expresses the efficiency of industrial production under environmental constraints. It is an effective means to characterize the relationship between industrial development and the ecological environment (Lin \&Zhu 2020, Zhou et al. 2018). IEE can take into account the relationship between industrial economic material exchange and energy conversion and comprehensively evaluates the overall status of industrial economy, energy consumption, and environmental benefits. It is of great significance for transforming the traditional industrial development model, promoting green industrial development, and supporting the construction of an ecological civilization in China.

Scholars have conducted research on IEE mainly from the following aspects: First, at the regional scale, recent research of IEE has mainly focused on spatiotemporal changes in different countries and provinces. For example, Marques et al. (2019) explored the IEE of 11 EU countries from 1997 to 2015. Zhou et al. (2020) studied the eco-efficiency of 31 industrial sectors in China. Zhang et al. (2017a) 
analyzed the IEE of 30 provinces (autonomous regions and municipalities) in China from 2005 to 2013. Second, in terms of methodology, scholars usually adopt the traditional DEA model (Shah et al. 2020, Wu et al. 2015, Zhang et al. 2008) for quantitative evaluation of the IEE. This method has strong objectivity and effectively avoids the interference of human factors, but when the value of each effective DMU calculated by the DEA model is 1, it is impossible to compare and distinguish effective DMUs. Finally, in terms of influencing factors, the Panel Tobit model and other methods are mostly used to explore the level of economic development (Haoran et al. 2019, Liu et al. 2020a), technological progress (Chen et al. 2019), foreign investment (Zhao et al. 2018), environmental regulation (Liu et al. 2020b), industrial structure (Wencong et al. 2018, Zhou et al. 2019), and other factors on IEE.

However, there have been relatively few studies of the effects of economic transformation on IEE. Globalization, marketization, and decentralization, as the three important forces of economic transformation, play an important role in reconstructing the spatial pattern of China's regional economy. Since its reform and opening up, China's industrialization process has also been deeply affected by economic transformation. Therefore, it is of great practical significance to explore IEE in the background of economic transformation. In addition, ecological protection and high-quality economic development in the Yellow River Basin was established as a major national strategy in September 2019 (Wang et al. 2021). However, the ecological environment of the Yellow River Basin is extremely fragile, and the heavy chemical industry is the development pillar of many provinces in the basin. The continuous development of heavy chemical industry has caused serious pollution in the ecological environment of the Yellow River Basin (Wang et al. 2020). Therefore, it is of great significance to explore the impact mechanism of IEE in the background of economic transformation to promote the ecological environment protection and high-quality development in the Yellow River Basin. 
River Basin from 2008 to 2017 and reveal its spatial distribution characteristics. The panel regression model was used to analyze the influencing factors of the IEE of the Yellow River Basin in the background of economic transformation. Compared with other studies, this study was advanced in the two aspects that follow. (1) Based on the relationship between economic transformation and IEE, a theoretical analysis framework of the impact of economic transformation on IEE was constructed. (2) The SuperEfficiency DEA model was introduced to evaluate the IEE, which addresses the problem that it is impossible to compare multiple effective DMUs when the calculation results of the traditional DEA model show that multiple effective DMUs are 1.

The other parts of this paper were arranged as follows. The second section describes the theoretical framework of economic transformation and IEE. The third section is the overview of the research area, model methods, and data sources. The fourth section is the research results and discussion. The fifth section is the summary of the research results.

\title{
2. Economic transformation and IEE
}

\author{
China's economy has experienced a transformation from planned economy to market economy, from
} closed development to opening up, and into the process of economic globalization. Economic transformation generally refers to the process of globalization, marketization, and decentralization. In recent years, experts and scholars have gradually realized the important role of economic transformation and have explored regional economic development (Jiya et al. 2020), industrial pollution (Zhiqing et al. 2018), and land use (Huang et al. 2015, Liu et al. 2018) from the perspective of economic transformation. Therefore, this study attempted to explore the impact mechanism of globalization, marketization, and decentralization on the IEE of cities in the Yellow River Basin from the perspective of economic 
transformation.

Globalization plays a vital role in promoting China's industrialization, and its impact on IEE is mainly characterized by foreign direct investment (FDI) (Pao \&Tsai 2011). FDI may have a positive or negative impact on IEE. On the one hand, FDI may have a positive impact on the IEE of developing countries (Feng 2014); the "pollution halo" hypothesis posits that foreign-funded enterprises may bring advanced equipment and technology to developing countries and promote the industrial technology upgrading of developing countries through the technology spillover effect so as to reduce energy consumption and pollution emissions (Jiang et al. 2019). On the other hand, FDI may have a negative impact on the IEE of developing countries (Lan et al. 2012, Liu et al. 2017b); the "pollution haven" hypothesis holds that the migration of foreign-funded enterprises from developed countries to developing countries with less environmental regulation not only promotes the economic growth of developing countries, but it also aggravates the local resource and energy consumption and leads to an increase in pollutant emissions and the deterioration of the ecological environment (Bao et al. 2015).

The effect of marketization on IEE is mainly reflected in promoting the redistribution of elements among industrial production sectors and promoting the reform of the market system. Marketization of the allocation of resources can break barriers to the flow of resources, promote the cross-regional and cross-industry flow of resources, and improve the efficiency of the allocation of production factors, which is conducive to reducing the cost of obtaining production factors, improving the survival ability of enterprises, and improving the production efficiency of enterprises (Campos \&Horváth 2012, Merlevede 2003). Moreover, Yi et al. (2015) believe that marketization can promote reform of the market system, which is conducive to attracting foreign-funded enterprises, introducing advanced industrial technology and management experience, promoting industrial enterprises' production efficiency, and reducing 
industrial pollution emissions.

Decentralization is also an important feature of China's economic transformation. China's decentralization process endows local governments with more independent development rights and also makes local governments bear the responsibility of regional economic development (Yin et al. 2018). At present, there are mainly three views on the effect of decentralization on IEE. One view holds that decentralization is conducive to the improvement of IEE; decentralization refers to the transfer of economic and financial power from the central government to the local governments, which is conducive to improving the allocation efficiency of local resources and reducing industrial pollution emissions (Chen \&Chang 2020, Mu 2018). Another view is that decentralization is not conducive to improving IEE. In order to improve the performance in promoting local economic development, local governments relaxed the regulatory environment to gain more space for economic development, thus promoting the increase of industrial pollution emissions (Zhang et al. 2017b). The last point of view is that the relationship between decentralization and IEE is non-linear. Under fiscal decentralization, in order to improve political performance, local governments must not only promote local economic development, but also improve the quality of the local ecological environment (Yang et al. 2020). Some scholars have found a nonlinear relationship between decentralization and pollution emissions through research (Cheng et al. 2019, Liu et al. 2017a).

This study was based on the theoretical research of economic transformation and took into account the regional economic development level and industrial development status of the Yellow River Basin. In addition, based on the existing research results (Guan \&Xu 2016, HA et al. 2020, Ren et al. 2020), and by adding basic factors such as industrial structure, economic development level, scientific and technological innovation, and population and industrial agglomeration, this study constructed a 


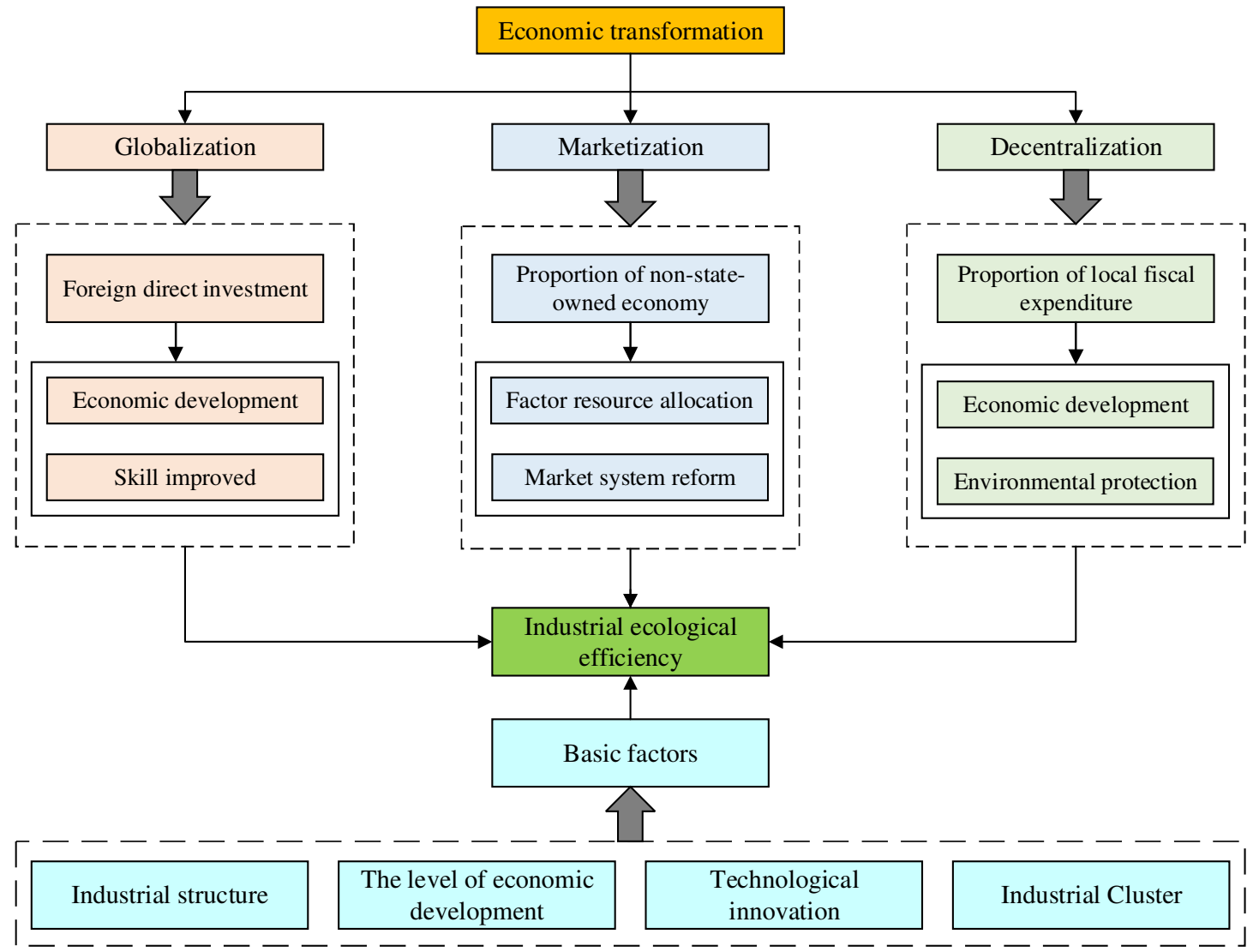

Fig. 1. Theoretical analysis framework of Economic transformation and IEE.

\section{Research setting and methodology}

\subsection{Study area}

The Yellow River Basin originates in the northern foot of Bayankala Mountain, flows eastward through Qinghai, Sichuan, Gansu, Ningxia, Inner Mongolia, Shaanxi, Shanxi, Henan, and Shandong, and then flows into the Bohai Sea from Kenli County of Shandong Province. In order to ensure the continuity of the region and learn from the definition of the Yellow River Basin in the study of physical geography and social economy by relevant scholars (Zhang \&Miao 2020), we considered that Sichuan province belongs to the Yangtze River Basin, and the East Four Leagues of Inner Mongolia belong to Northeast China, so they were not included. Therefore, in this study, the remaining 8 provinces and 91 cities (prefectures and leagues) were selected as research objects (Fig. 2). Referring to the Yellow River 


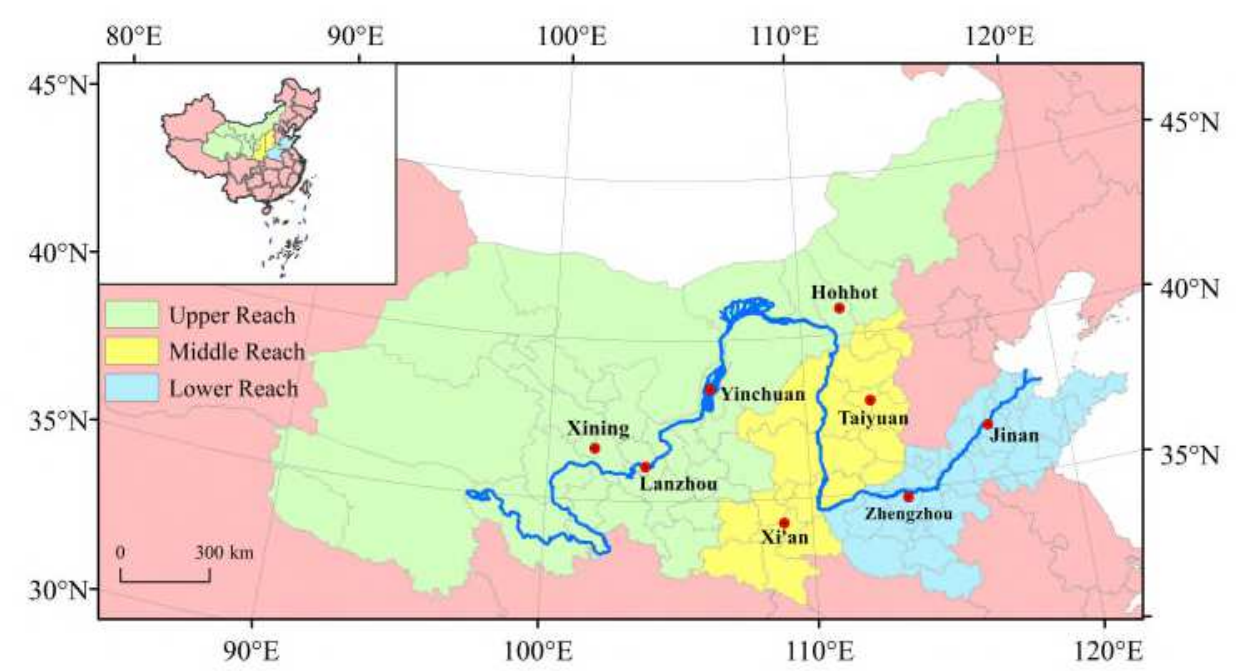

Fig. 2. Scope of the Yellow River Basin.

\subsection{Methodology}

(1) Super-efficiency DEA model

In the 1970s, American scholars Charnes, Cooper, and Rhodes first proposed the DEA model. This model is an analysis model based on "relative efficiency evaluation," which can better eliminate the interference of human factors when evaluating the efficiency of DMUs (Charnes et al. 1979), However, in the model calculation results, when the value of each effective DMU calculated by the DEA model is andPetersen (1993) proposed a Super-efficiency DEA model which was based on the traditional DEA 
used the Super-efficiency DEA model to evaluate the IEE of cities in the Yellow River Basin. The Superefficiency DEA model is as follows:

$$
\text { s.t. }\left\{\begin{array}{c}
\operatorname{Min} \theta \\
\sum_{i=1, j \neq 1}^{n} X_{j} \lambda_{j}+s^{-}=\theta X_{0} \\
\sum_{i=1, j \neq 1}^{n} X_{j} \lambda_{j}-s^{+}=Y_{0} \\
\lambda_{j} \geq 0, J=1,2, \Lambda k-1, k \\
s^{-} \geq 0, s^{+} \geq 0
\end{array}\right.
$$

where $\theta$ is the value of IEE; $X$ and $Y$ are input variables and output variables, respectively; $\lambda$ is the combination proportion of effective DMUs to represent the return of scale of DMUs; $S^{-}$and $s^{+}$are slack variables and residual variables, respectively. When $\theta>1$, the IEE is optimal; when $\theta<1$, the IEE is not optimal.

(2) Exploratory spatial data analysis (ESDA)

The ESDA mainly includes global spatial autocorrelation (Moran \&P.A.P 1948) and local spatial autocorrelation (Getis \&Ord 1992). Global spatial autocorrelation is a generalization of the spatial dependence of economic phenomena or attributes with adjacency in a certain space. The most commonly used correlation index is global Moran ' $s I$.

$$
I=\frac{n \sum_{i=1}^{n} \sum_{j=1}^{n} w_{i j}\left(x_{i}-\bar{x}\right) \times\left(x_{j}-\bar{x}\right)}{\left(\sum_{i=1}^{n} \sum_{j=1}^{n} w_{i j}\right) \times \sum_{i=1}^{n}\left(x_{i}-\bar{x}\right)^{2}}
$$

where $I$ is the global Moran index; $n$ is the number of units in the analysis space; $x_{i}$ and $x_{j}$ are the observed values of space unit $i$ and $j$, respectively; $\bar{x}$ is the mean value of observation values of all space units; and $w_{i j}$ is the spatial weight matrix of spatial elements $i$ and $j$.

Hot spot analysis is a judgment method of local spatial autocorrelation, which can directly reflect the agglomeration of high and low values in a certain area and the degree of agglomeration (Chen et al. 


$$
G_{i}^{*}=\frac{\sum_{j=1}^{n} W_{i j}(d) X_{j}}{\sum_{j=1}^{n} X_{j}}(i \neq j), \quad Z\left(G_{i}^{*}\right)=\frac{G_{i}-E\left(G_{i}^{*}\right)}{\sqrt{\operatorname{Var}\left(G_{i}^{*}\right)}},
$$

where $W_{i j}$ is the weight of space, and is 1 if the space is adjacent or 0 if the space is not adjacent. $E\left(G_{i}^{*}\right)$ and $\operatorname{Var}\left(G_{i}^{*}\right)$ are the mathematical expectation and variance of $G_{i}^{*}$, respectively. If the value of $Z\left(G_{i}^{*}\right)$ is positive and significant, the surrounding values of the spatial uniti are high, and it is a hot spot in the region; if the value of $Z\left(G_{i}^{*}\right)$ is negative and significant, the unit is a cold spot in the region.

\subsection{Dependent and independent variables}

Based on the core idea of "low input and high output" and referring to relevant research results (J. et al. 2009, Tong et al. 2020), combined with the industrial development status of various regions in the Yellow River Basin, the industrial power consumption and industrial wastewater discharge were taken as the input index of resource consumption, the industrial $\mathrm{SO}_{2}$ emission and industrial dust emission were taken as the input index of environmental pollution, and the total industrial output value was taken as the output index. Descriptive statistical results of the input and output indicator data are shown in Table 1.

Table 1. Descriptive statistics of input and output data.

\begin{tabular}{ccccccc}
\hline Indicators & Variables & Unit & Mean & Std. Dev. & Min & Max \\
\hline Input & Industrial & 100 million & 62.36 & 77.41 & 0.13 & 991.61 \\
& electricity & $\mathrm{KW} \cdot \mathrm{h}$ & & & & \\
consumption & & & & & \\
& Industrial & 10 kilo-tons & 5424.54 & 5057.39 & 99 & 33007 \\
wastewater & & & & & \\
discharge & & & & & \\
Industrial $\mathrm{SO}_{2}$ & ton & 63699.62 & 51176.44 & & \\
\hline & & & & & \\
\hline
\end{tabular}




\begin{tabular}{ccccccc}
\hline & $\begin{array}{c}\text { Industrial } \\
\text { smoke and dust }\end{array}$ & ton & 49558.46 & 228183.33 & 450 & 5168812 \\
& & & & & & \\
& emissions & & & & & \\
Output & Industrial & 100 million & $2,709.07$ & $3,161.44$ & $16,811.83$ \\
& output & yuan & & & & \\
\hline
\end{tabular}

197

In terms of model construction, based on the perspective of economic transformation, this study identified IEE as the dependent variable, and globalization, marketization, and decentralization as the core explanatory variables. In addition, by referring to the relevant research literature (Guan \&Xu 2016, HA et al. 2020, Ren et al. 2020) combined with the development status of the Yellow River Basin and the availability of data, the five indicators of industrial structure, economic development level, scientific and technological innovation, population agglomeration, and industrial agglomeration were selected as the control variables. The panel regression model was constructed to explore the driving factors of IEE in the Yellow River Basin in the background of economic transformation, and the relevant variables and their meanings are shown in Table 2. In order to avoid the influence of heteroscedasticity on the regression results, the index data were logarithmically processed, and the descriptive statistical results of the indicator data are shown in Table 3.

Table 2. Explanation of urban IEE and impact indicators.

\begin{tabular}{|c|c|c|c|}
\hline Variables & Indicators & Definition & Codes \\
\hline Dependent variable & IEE & IEE value & ep \\
\hline \multirow[t]{6}{*}{ Explanatory variable } & Globalization & FDI/urban population & glo \\
\hline & Marketization & Non-state-owned economy / Total & mar \\
\hline & & industrial output value & \\
\hline & Decentralization & Urban per capita fiscal & dec \\
\hline & & expenditure/National per capita fiscal & \\
\hline & & expenditure & \\
\hline \multirow[t]{6}{*}{ Control variable } & Industrial structure & The proportion of secondary industry in & str \\
\hline & & GDP & \\
\hline & The level of economic & GDP per capita & $p g d p$ \\
\hline & development & & \\
\hline & Technological & The proportion of science and technology & tec \\
\hline & innovation & expenditure to local fiscal expenditure & \\
\hline
\end{tabular}




\begin{tabular}{ccc}
\hline $\begin{array}{c}\text { Population } \\
\text { agglomeration } \\
\text { Industrial Cluster }\end{array}$ & City population/area & pop \\
& Industrial output value/area & agg \\
\hline
\end{tabular}

Table 3. Descriptive statistics of variables.

\begin{tabular}{cccccc}
\hline Indicators & Observation & Mean & Std. Dev. & Min & Max \\
\hline Inep & 800 & 0.182 & 0.196 & 0.006 & 1.263 \\
Inglo & 800 & -1.183 & 1.815 & -6.604 & 2.550 \\
Inmar & 800 & 1.234 & 1.571 & -5.464 & 4.599 \\
lndec & 800 & 1.320 & 0.485 & 0.078 & 3.170 \\
Instr & 800 & -0.315 & 1.529 & -4.577 & 2.918 \\
Inpgdp & 800 & 3.895 & 0.273 & 2.608 & 4.471 \\
Intec & 800 & 2.347 & 0.068 & 2.103 & 2.502 \\
Inpop & 800 & 7.042 & 1.662 & 1.826 & 9.987 \\
lnagg & 800 & 1.692 & 0.230 & 0.468 & 1.976 \\
\hline
\end{tabular}

\subsection{Data Sources}

\section{Results and discussion}

223 4.1. The temporal evolution characteristics of IEE 

an elongated S-shaped evolutionary trends. The mean IEE of the whole region rose from 0.102 in 2008 to 0.316 in 2016 , when it reached its highest value, and fell to 0.291 in 2017 , indicating that the IEE of the Yellow River Basin began to deteriorate after a long period of improvement. In the past few years, local industrial restructuring in the Yellow River Basin has hampered the development of local enterprises, resulting in a sharp drop in the production efficiency of local enterprises in a short period of time. Among them, the mean IEE of the upper reaches was always lower than that of the whole basin, and the mean IEE of the middle reaches showed an evolution trend of "first rising and then declining," which was consistent with the evolution curve of the whole basin. The mean IEE of the lower reaches was always higher than the mean IEE of the whole basin. Moreover, the mean IEE of the lower reaches had been steadily rising before 2015, jumped in 2016, and then stabilized in 2017. In summary, there were obvious regional differences in the IEE of the Yellow River Basin, which may have been closely related to the regional differences in the level of economic development. The higher the level of economic development, the higher the IEE. Therefore, it is important to promote the high-quality development of and upgrading, and reduce industrial pollution emissions. 


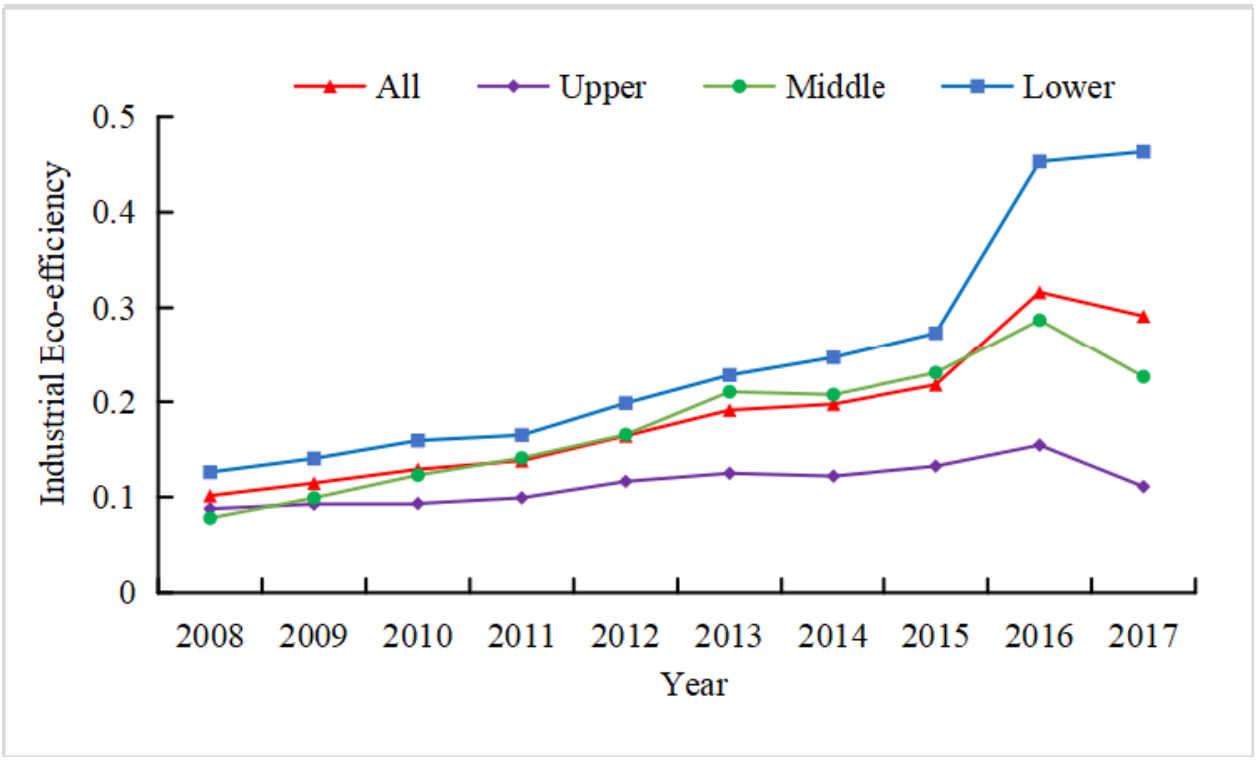

Fig. 3. The mean IEE in the Yellow River Basin from 2008 to 2017.

the Yellow River Basin, four years (2008, 2011, 2014, and 2017) were selected, and the kernel density

estimation method was used to analyze the regional differences of IEE in the Yellow River Basin in different periods (Fig. 4). From 2008 to 2017, the kernel density curve of the whole basin showed the characteristics of a long-tail rising peak, the peak gradually decreased, and the peak type changed from narrow peak to wide peak. The change interval increased continuously, which indicated that the overall level of IEE in the Yellow River Basin was improving, but the regional gap was widening. In the middle and lower reaches of the region, the kernel density curve showed that the main peak gradually shifted to the right, the peak decreased continuously, and the peak changed from narrow peak to wide peak, which indicated that the level of IEE in the middle and lower reaches of the region was increasing while the regional gap was widening. The kernel density curve of the upper reaches showed that the peak value gradually decreased and the right tailing phenomenon gradually weakened, which indicated that the overall level of IEE in the upper reaches was decreasing while the regional gap was gradually decreasing. 

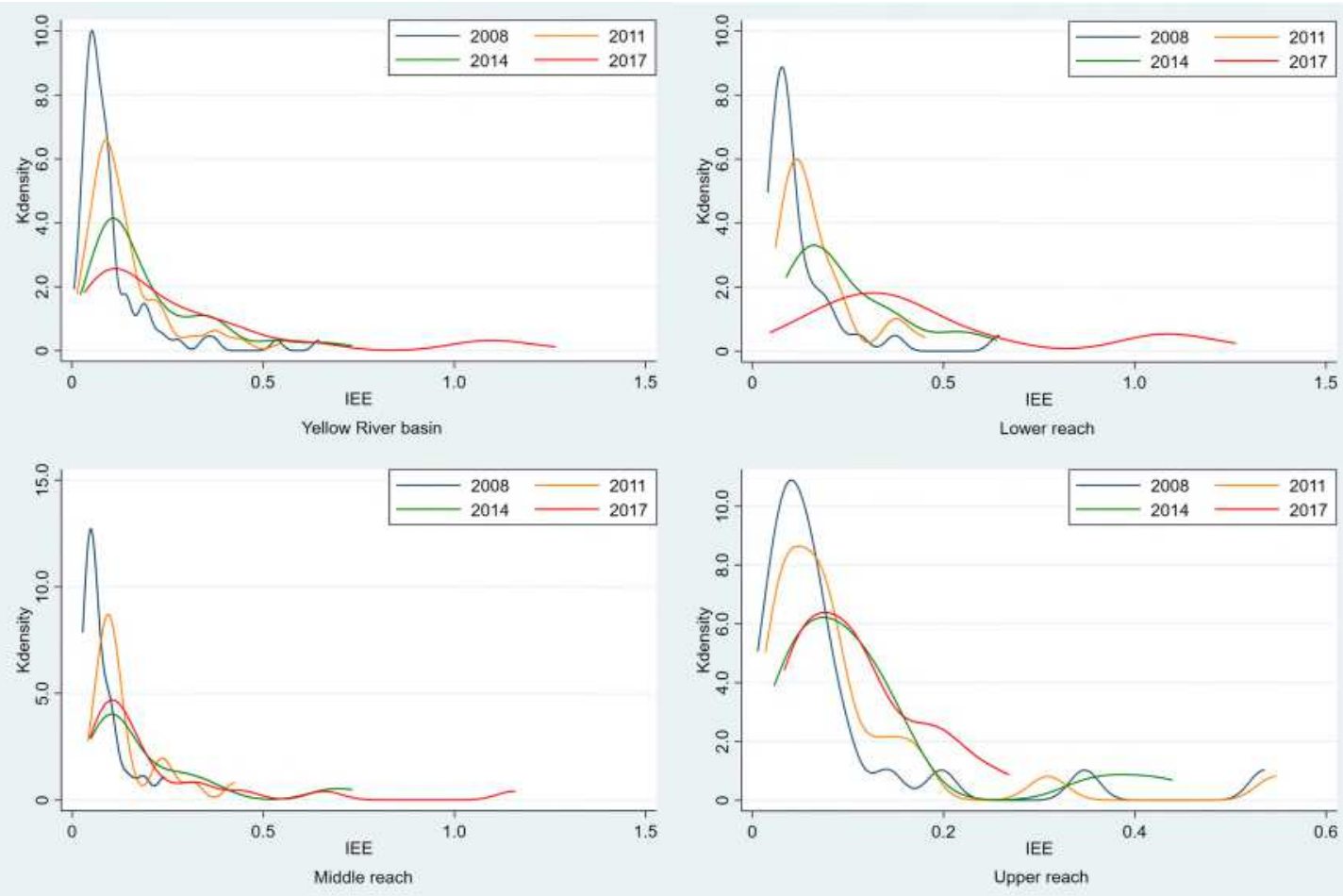

Fig. 4. Regional differences in IEE from 2008 to 2017.

\subsection{The spatial evolution characteristics of IEE}

The spatial visualization results of IEE in the Yellow River Basin in 2008, 2011, 2014, and 2017 are shown in Fig. 5. The higher IEE zone in the Yellow River Basin showed the spatial distribution characteristics of "scattered Mosaic." The overall level of IEE presented a spatial differentiation pattern, in which lower reaches were higher than middle reaches and higher than upper reaches.

Specifically, in 2008, the higher IEE zone included Yantai and Weihai in the lower reaches and Ordos and Qingyang in the upper reaches. In 2011, the higher IEE zone included Qingdao, Yantai, Weihai, and Dongying in the lower reaches, Luliang in the middle reaches, and Qingyang in the upper reaches. In 2014, the higher IEE zone included Qingdao, Yantai, Weihai, and Dongying in the lower reaches, and Weinan and Shangluo were added in the middle reaches. In 2017, the higher IEE zone was transformed into six cities in the lower reaches, including Qingdao, Weihai, Dongying, Puyang, Zhoukou, and Luohe, and Ankang City was added in the middle reaches. The trend surface analysis was used to identify the geographic trends of the IEE in the Yellow River Basin from 2008 to 2017. The trend surface analysis 
results are shown in Fig. 6. The IEE of the Yellow River Basin in the east-west direction evolved from "high at both ends and low in the middle" in 2008 to "high in the east and low in the west" in 2017. In the north-south direction, the IEE changed from the inverted "U" pattern in 2008 to the gradient spatial pattern of "high in the south and low in the north" in 2017, and the curvature of the curve decreased significantly, demonstrating that the IEE of the Yellow River Basin improved significantly during the research period, and the southeast region became the high-value area of IEE, while the northwest region became the weak area of IEE.

The IEE in the lower reaches of the Yellow River Basin was relatively stable and at a high level, while the IEE in the middle and upper reaches of the Yellow River Basin was relatively low. Qingdao, Yantai, Weihai, and other coastal cities in the lower reaches had an early start in industrial development and a high level of economic development. On the one hand, the good industrial base has strongly promoted the development of regional economy. On the other hand, the higher level of economic development has forced the upgrading of regional industrial technology, which is conducive to the higher level of IEE in the lower reaches. Shanxi and Shaanxi provinces in the middle reaches are both large in coal resources, and the traditional industrial development model of "high consumption and high pollution" has been dominant for a long time, resulting in low IEE. The ecological environment in the upper reaches is very fragile. Owing to the late start of industrial development, industrial technology and management experience are relatively backward, and the level of IEE in this region is far lower than that in the middle and lower reaches. 

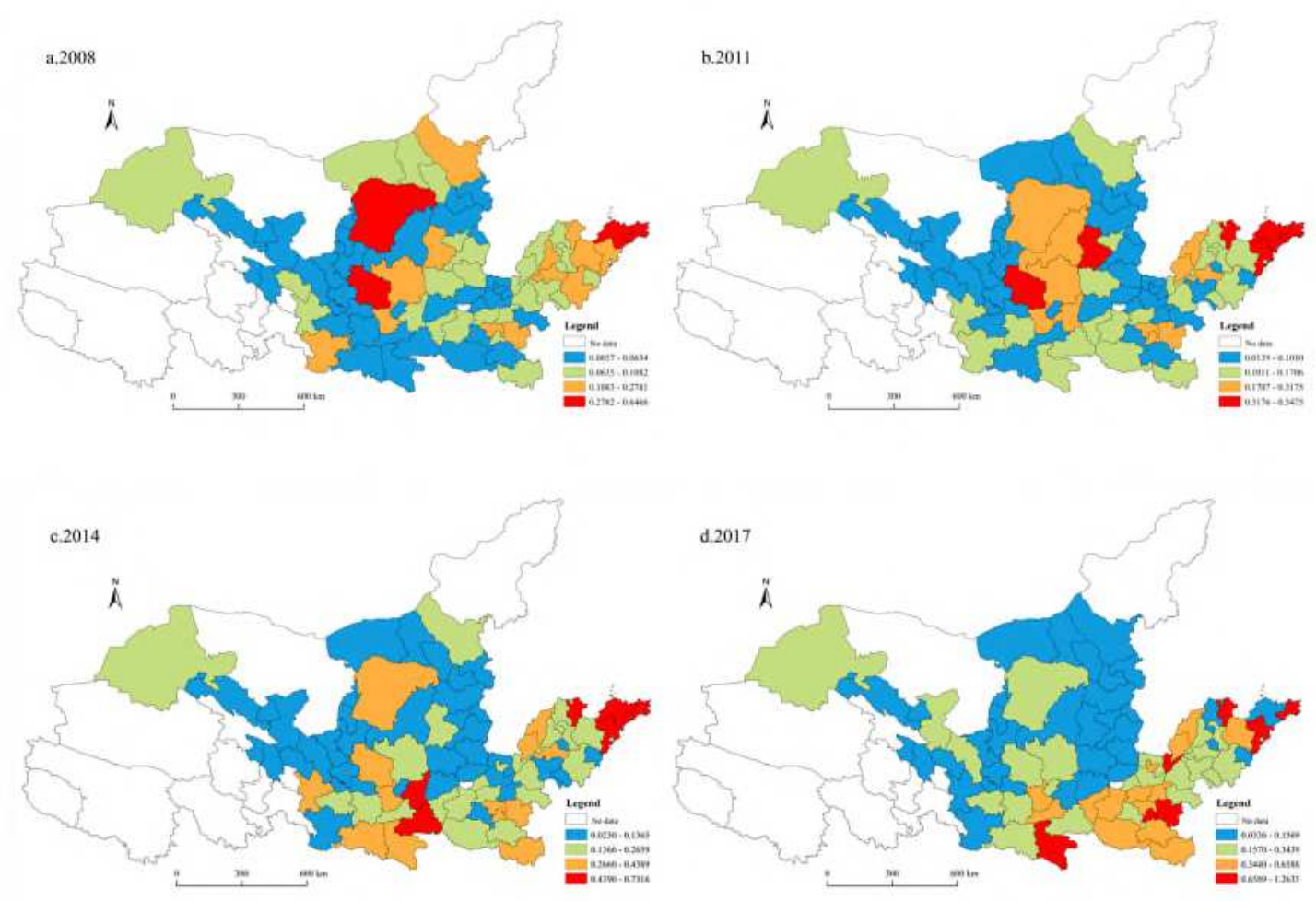

Fig. 5. The IEE of the Yellow River Basin in 2008, 2011, 2014 and 2017.
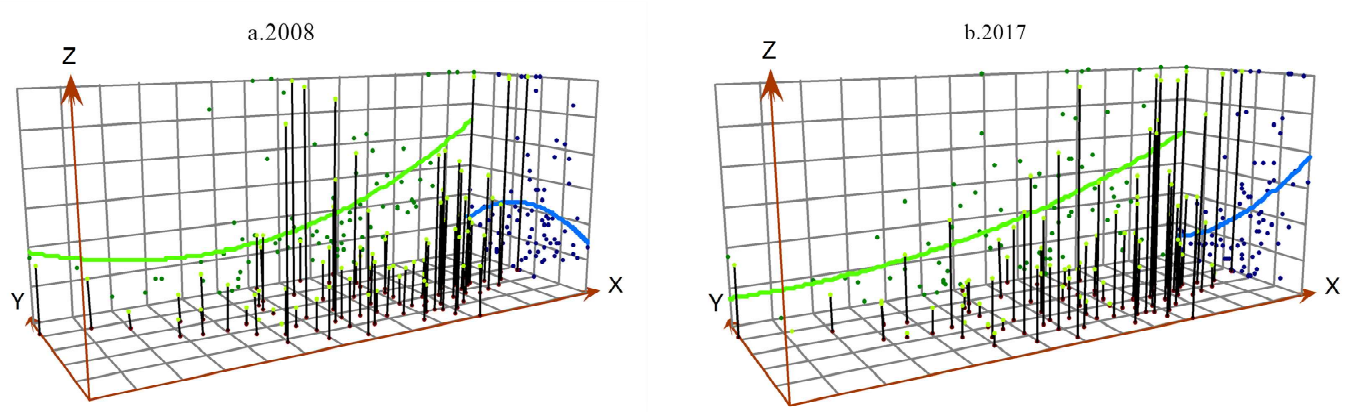

Fig. 6. The overall trend of IEE in 2008 and 2017.

\subsection{Spatial correlation analysis of IEE}

The global Moran's I index calculated by GeoDa software is shown in Table 4. The global Moran's

I of the IEE in the Yellow River Basin from 2008 to 2017 were all positive and passed the significance test at the level of $1 \%$, indicating that there was a significant and positive spatial autocorrelation of the IEE in the Yellow River Basin during the research period. At the same time, the global Moran's $I$ index presented an evolutionary characteristic of "rising first and then decreasing," reflecting that the IEE of the Yellow River Basin has gone through a process of increasing spatial agglomeration and then 
decreasing spatial agglomeration.

Table 4. Global Moran's I Index of IEE in the Yellow River Basin.

\begin{tabular}{cccc}
\hline Year & Moran's $I$ & $Z$-score & $P$-value \\
\hline 2008 & 0.2716 & 5.2292 & 0.0020 \\
2009 & 0.3170 & 6.2012 & 0.0020 \\
2010 & 0.2884 & 5.1526 & 0.0020 \\
2011 & 0.2892 & 5.0120 & 0.0020 \\
2012 & 0.2494 & 4.4847 & 0.0020 \\
2013 & 0.3667 & 6.4440 & 0.0020 \\
2014 & 0.3279 & 5.2251 & 0.0020 \\
2015 & 0.2639 & 4.3143 & 0.0020 \\
2016 & 0.3348 & 6.2003 & 0.0020 \\
2017 & 0.3234 & 5.5456 & 0.0020 \\
\hline
\end{tabular}

In order to further explore the local spatial agglomeration of IEE in the Yellow River Basin, the Getis-Ord Gi* index of IEE of cities in the Yellow River Basin was measured by ArcGIS software, and the spatial distribution map of cold and hot spots was created (Fig. 7). There was an obvious "spatial club" phenomenon in the distribution of cold and hot spots of urban IEE in the Yellow River Basin. The hot spots were mainly concentrated in the middle and lower reaches of the Yellow River Basin, while the cold spots were mainly concentrated in middle and upper reaches. Specifically, in 2008, Qingdao, Yantai, Weihai, Weifang, Dongying, and Yulin were hot spots of IEE, while Zhongwei and Baiyin were cold spots of IEE. In 2011, Zibo City, Yan 'an City, and Tongchuan City were added as hot spots on the basis of 2008 IEE hot spots, while Wuwei City, Lanzhou City, Dingxi City, and Yinchuan City were added as cold spots on the basis of 2008 IEE cold spots. In 2014, the hot spots of IEE evolved into 11 cities (i.e., Qingdao, Yantai, Weihai, Weifang, Dongying, Tongchuan, Weinan, Shangluo, Xi'an, Xianyang, and Ankang), while the cold spots evolved into 10 cities (Shuozhou, Xinzhou, Taiyuan, Yangquan, Jinzhong, Changzhi, Yinchuan, Wuzhong, Zhongwei, and Wuwei). In 2017, IEE hot spots continued to increase to 19 cities, including Qingdao, Yantai, Weihai, Zhengzhou, and Zhoukou, and cold spots increased to 11 cities, including Shuozhou, Xinzhou, Taiyuan, Yangquan, Zhongwei, and Wuzhong. From the evolution 

the state of random distribution, reflecting that the connection degree of IEE among the cities in the Yellow River Basin was not high during the research period. The number of hot spots was increasing and mainly concentrated in the lower reaches, while the cold spots were concentrated in the middle and upper reaches. Therefore, the key to improving the IEE of the Yellow River Basin is to strengthen the interaction between the hot spots of IEE in the lower reaches and other regions and give full play to the radiationdriven role of the region.
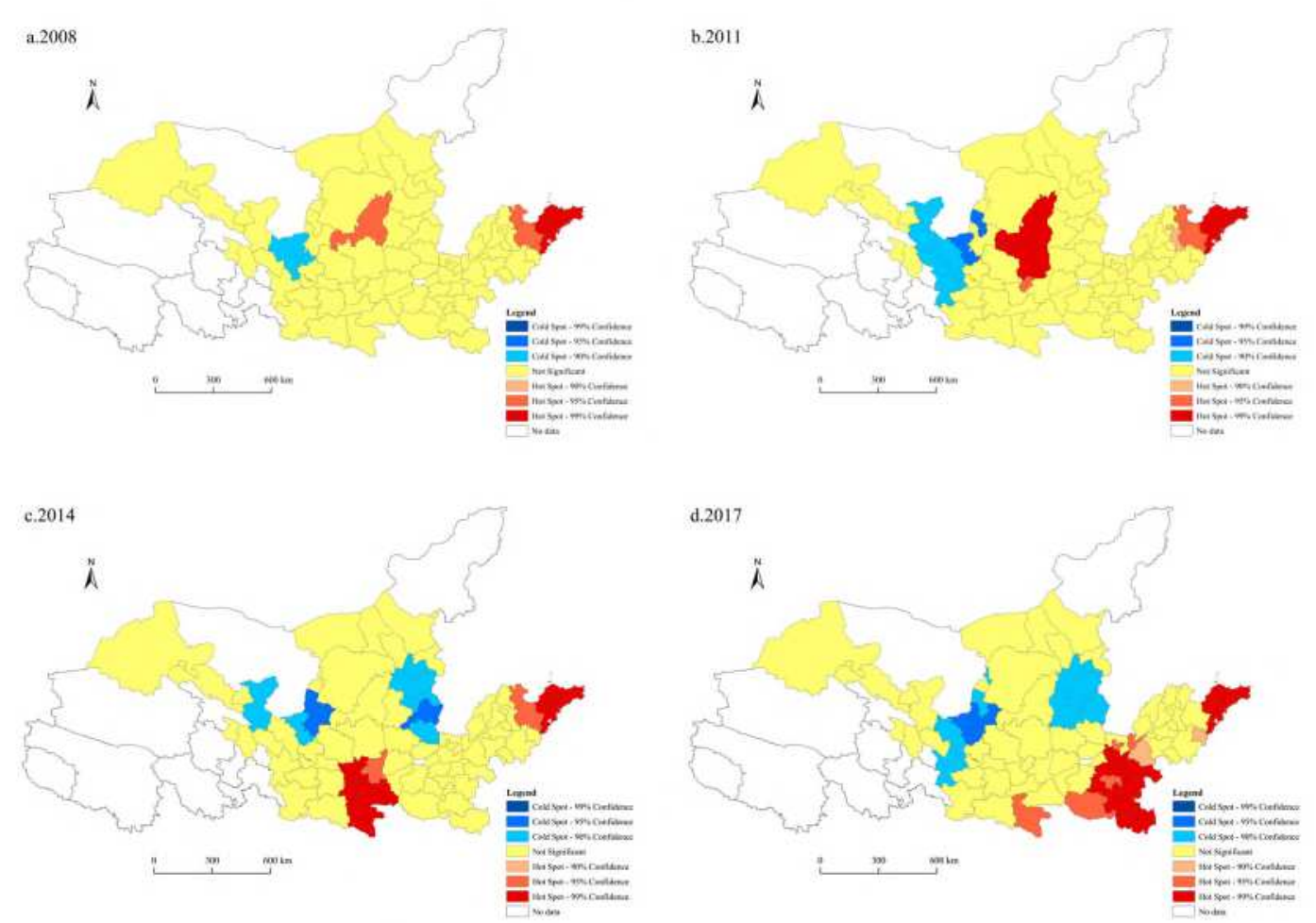

Fig. 7. Spatial evolution map of cold and hot spots of IEE in the Yellow River Basin.

4.4. The Influence mechanism of IEE in the background of economic transformation 
be suitable for influencing factor analysis in the whole basin and the middle reaches, while the random effect model was found to be suitable for influencing factor analysis in the upper and lower reaches. The regression results for the influencing factors are presented in Table 5.

(1) Globalization had a positive effect on the IEE of the lower reaches in the research period, which was consistent with the research conclusions of Wang andChen (2014), but it was not significant for the upper reaches, middle reaches and the whole basin. Specifically, the impact coefficient of globalization on the IEE in the lower reaches of the Yellow River Basin was 0.1038, and it passed the test at the significance level of 5\%, indicating that every $1 \%$ increase in per capita FDI caused the IEE in the lower reaches of the Yellow River Basin to increase by $0.1038 \%$. Shandong Province, in the lower reaches, is located in the eastern coastal economic zone, with a relatively high degree of globalization and strong attraction to foreign-funded enterprises, which is conducive to promoting the economic development of the region; Henan Province, in the lower reaches, has a large area, with the east adjacent to the coastal economic zone and the south adjacent to the Yangtze River Economic Zone, which promotes the diffusion of foreign-funded enterprises to the region. Thus, FDI could promote the economic growth, industrial technology progress, and industrial structure adjustment in the lower reaches, improve the level of industrial technology and industrial production efficiency, and promote the improvement of IEE in the lower reaches, which confirmed the "halo effect" of FDI. The effect of globalization on the IEE of the whole basin, middle reaches, and upper reaches was not significant. The middle and upper reaches of the Yellow River Basin are located in the central and western inland areas of China. The degree of globalization is low, the level of economic development is relatively slow, and the attraction to foreignfunded enterprises is relatively insufficient, which makes the investment of foreign-funded enterprises relatively insufficient. Moreover, owing to the fragile ecological environment in the middle and upper 
reaches of the Yellow River Basin, relevant government departments give more management and constraints to foreign-invested enterprises when introducing foreign capital, which further increases the difficulty of attracting foreign capital and makes the impact of globalization on IEE insignificant. In addition, the impact of globalization on the IEE of the Yellow River Basin was not significant in the middle and upper reaches, so the impact of globalization on the IEE of the whole basin was not significant. (2) Marketization had a positive effect on the IEE of the lower reaches during the research period, which was consistent with the research conclusion of Yi et al. (2015), while the effect on the middle reaches, upper reaches, and the whole basin was not significant. Specifically, the impact coefficient of marketization on the IEE of the lower reaches was 0.0331, and it passed the significance test at the level of $10 \%$. This showed that the degree of marketization had a positive impact on the IEE of the lower reaches. Every $1 \%$ increase in the proportion of non-state-owned economy caused the IEE of the lower reaches to increase by $0.0331 \%$. Shandong and Henan provinces in the lower reaches are located in the eastern coastal economic zone and its adjacent regions respectively. The degree of globalization and marketization in these regions is relatively high, which is conducive to promoting the market system reform in this region, enhancing its attraction to foreign enterprises, and thus promoting regional industrial and technological progress. Marketization is conducive to promoting the cross-regional and cross-industry flow of factor resources in the lower reaches, attracting and retaining foreign-invested enterprises, promoting the adjustment and optimization of industrial structure in the lower reaches, thus promoting the improvement of IEE in the region. The effect of marketization on the IEE of the middle reaches, upper reaches, and the whole basin was not significant. The middle and upper reaches of the Yellow River Basin, owing to their depth in China's inland regions, are relatively less open to the outside world, less non-state-owned enterprises, and less globalized and marketized than the lower reaches. 
Moreover, Shanxi and Shaanxi provinces, in the middle reaches of the Yellow River Basin, are both big coal resources provinces. In the process of industrial development, they have a strong dependence on coal resources, a lack of attraction to foreign-funded enterprises, and a low degree of marketization. The upper reaches are an important ecological environment protection area in China, and the government has strong environmental supervision on local enterprises, which is not conducive to the introduction of foreign-funded enterprises. Therefore, the proportion of non-state-owned enterprises was low. In addition, compared with the Yangtze River Basin, the water flow of the Yellow River Basin is small and unstable, the navigation capacity is poor, and the Yellow River Basin lacks gateway cities and hub city clusters like Shanghai and the Yangtze River Delta, so it is difficult to form the Yellow River economic belt, which is not conducive to regional globalization and marketization. Therefore, the effect of marketization on the IEE of the whole basin was not significant.

(3) Decentralization had a negative effect on the IEE of the whole basin and the middle reaches during the research period, which was consistent with the research conclusion of Zhang et al. (2017b), and had a positive promoting effect on the upper reaches, which was consistent with some previous research conclusions (Chen \&Chang 2020, Mu 2018). However, the effect on the lower reaches was not significant. Specifically, the impact coefficient of decentralization on the IEE of the whole basin was 0.1495 , and it passed the significance test at the level of 5\%. Every $1 \%$ increase in the degree of decentralization would reduce the IEE of the whole basin by $0.1495 \%$. The impact coefficient of decentralization on the IEE of the middle reaches was -0.3972 , and it passed the significance test at the level of $5 \%$. Every $1 \%$ increase in the degree of decentralization would reduce the IEE of the middle reaches by $0.3972 \%$. The degree of globalization and marketization in the middle reaches of the Yellow River Basin is relatively low, and the degree of decentralization is relatively high. In the process of 
401

402

403

404

405

406

407

decentralization, local governments often take measures to promote the rapid economic growth of the region, such as increasing enterprise taxes and relaxing the regulatory environment, which leads to the increase of enterprise production costs and pollution emissions, and then reduces the IEE. The impact coefficient of decentralization on the IEE of the upper reaches was 0.0678 , and it passed the significance test at the level of 5\%. Every $1 \%$ increase in the degree of decentralization would cause the IEE of the upper reaches to increase by $0.0678 \%$. The ecological environment in the upper reaches of the Yellow River Basin is very fragile, and the local government has a high degree of financial autonomy, which is beneficial for the local government to strengthen the control of regional ecological environment and to promote the protection of ecological environment in the upper reaches of the Yellow River Basin, which is consistent with the results of some previous studies (Chen \&Chang 2020, Hao et al. 2021). However, decentralization is conducive to improving the allocation efficiency of local resources, strengthening exchanges and cooperation with other regions, selectively introducing advanced industries and technologies, and contributing to the ecological environment protection and high-quality development of the upper reaches. The effect of decentralization on the IEE in the lower reaches was not significant, which may be because of the relatively high degree of globalization and marketization in the lower reaches, the relatively high level of economic development, and relatively weak control of local enterprises by the local government.

(4) Control variable analysis. The industrial structure had a significant negative effect on the IEE of the upper, middle, and lower reaches as well as the whole basin. This was in contrast to the fact that most areas of the Yellow River Basin were dominated by the development of heavy and chemical industry during the research period. A large number of environmental pollutants are discharged in the process of industrial production, thus reducing the IEE of the whole basin. The level of economic development had 
a significant positive effect on the IEE of the lower reaches and the whole basin, which is consistent with the results of some previous studies (Liu et al. 2020a). The level of economic development would promote the adjustment of regional industrial structure and the progress of industrial technology and then promote the improvement of IEE. However, the level of economic development in the middle and upper reaches of the region is relatively backward, so the impact on IEE was not significant. Scientific and technological innovation has a significant positive role in promoting the IEE of the lower reaches, which is consistent with the research conclusion of Chen et al. (2020). Scientific and technological innovation helps to promote the upgrading of industrial technology, improve the production efficiency of industrial enterprises, and promote the improvement of IEE. Population agglomeration plays a negative role in promoting the IEE of the lower reaches and the whole basin. There are many industrial enterprises in the area of population agglomeration; however, most of the industries in the Yellow River Basin are still dominated by the secondary industry, and the level of industrial technology and management experience is relatively backward, which makes the production efficiency of most industrial enterprises low. Industrial agglomeration has a significant positive effect on the IEE of the lower reaches, middle reaches, and the whole basin, which is consistent with the research conclusion of Shen andPeng (2020). Industrial agglomeration can effectively reduce the overall pollutant emission in the Yellow River Basin by its pollution control scale effect. However, industrial agglomeration can promote industrial technology upgrading through technology spillover effect, and then promote the improvement of IEE.

Table 5. Panel regression results of factors affecting IEE in the Yellow River Basin.

\begin{tabular}{ccccccccc}
\hline \multirow{2}{*}{ Variable } & \multicolumn{2}{c}{ All } & \multicolumn{2}{c}{ Lower } & \multicolumn{2}{c}{ Middle } & \multicolumn{2}{c}{ Upper } \\
\cline { 2 - 9 } & $\mathrm{fe}$ & $\mathrm{re}$ & $\mathrm{fe}$ & $\mathrm{re}$ & $\mathrm{fe}$ & $\mathrm{re}$ & $\mathrm{fe}$ & $\mathrm{re}$ \\
\hline \multirow{2}{*}{ Cons } & -0.1826 & -0.1918 & -0.3359 & 0.4431 & 2.4489 & 0.7252 & $-0.0658(-$ & $-0.0989(-$ \\
& $(-0.18)$ & $(-0.22)$ & $(-0.11)$ & $(0.22)$ & $(0.50)$ & $(0.30)$ & $0.13)$ & $0.21)$ \\
& -0.0168 & $-0.0388^{* * *}$ & 0.0634 & $0.1038^{* *}$ & $0.0848^{*}$ & 0.0050 & $-0.0134(-$ & $-0.0119(-$ \\
lnglo & $(-0.98)$ & $(-2.57)$ & $(1.34)$ & $(2.66)$ & $(1.77)$ & $(0.12)$ & $1.52)$ & $1.52)$ \\
\hline
\end{tabular}




\begin{tabular}{|c|c|c|c|c|c|c|c|c|}
\hline lnmar & $\begin{array}{l}0.0036 \\
(0.28)\end{array}$ & $\begin{array}{c}-0.0023 \\
(-0.24)\end{array}$ & $\begin{array}{l}0.0072 \\
(0.14)\end{array}$ & $\begin{array}{c}0.0331^{*} \\
(1.25)\end{array}$ & $\begin{array}{l}0.0056 \\
(0.18)\end{array}$ & $\begin{array}{c}-0.0064(- \\
0.25)\end{array}$ & $\begin{array}{c}-0.0019(- \\
0.33)\end{array}$ & $\begin{array}{c}-0.0001(- \\
0.01)\end{array}$ \\
\hline Indec & $\begin{array}{c}-0.1495^{* *} \\
(-2.51)\end{array}$ & $\begin{array}{l}0.0252 \\
(0.61)\end{array}$ & $\begin{array}{c}-0.2052(- \\
1.42)\end{array}$ & $\begin{array}{l}-0.0611 \\
(-0.54)\end{array}$ & $\begin{array}{c}-0.3972 * * \\
(-2.67)\end{array}$ & $\begin{array}{c}-0.1040(- \\
0.80)\end{array}$ & $\begin{array}{c}0.0594 * * \\
(2.00)\end{array}$ & $\begin{array}{c}0.0678 * * \\
(2.66)\end{array}$ \\
\hline lnstr & $\begin{array}{c}-0.0273^{*} \\
(-1.77)\end{array}$ & $\begin{array}{c}-0.0417^{* * *} \\
(-2.83)\end{array}$ & $\begin{array}{c}-0.0987 * * \\
(-2.36)\end{array}$ & $\begin{array}{c}-0.1310^{* * * *} \\
(-4.01)\end{array}$ & $\begin{array}{c}-0.0946 * \\
(-1.91)\end{array}$ & $\begin{array}{c}-0.0286(- \\
0.65)\end{array}$ & $\begin{array}{c}-0.0154 * \\
(-1.97)\end{array}$ & $\begin{array}{c}-0.0127^{*} \\
(-1.69)\end{array}$ \\
\hline $\ln p g d p$ & $\begin{array}{c}0.0518^{*} \\
(1.00)\end{array}$ & $\begin{array}{c}0.0971 * * \\
(2.07)\end{array}$ & $\begin{array}{c}0.2492 * \\
(1.68)\end{array}$ & $\begin{array}{c}0.1272 * * * \\
(3.76)\end{array}$ & $\begin{array}{l}0.1108 \\
(0.92)\end{array}$ & $\begin{array}{l}0.0351 \\
(0.31)\end{array}$ & $\begin{array}{l}0.0109 \\
(0.38)\end{array}$ & $\begin{array}{l}0.0082 \\
(0.30)\end{array}$ \\
\hline Intec & $\begin{array}{l}0.1936 \\
(0.54)\end{array}$ & $\begin{array}{l}0.2503 \\
(0.72)\end{array}$ & $\begin{array}{c}0.9937^{*} \\
(1.15)\end{array}$ & $\begin{array}{c}0.6069^{*} \\
(1.87)\end{array}$ & $\begin{array}{l}0.6727 \\
(0.87)\end{array}$ & $\begin{array}{l}0.1361 \\
(0.17)\end{array}$ & $\begin{array}{l}0.0399 \\
(0.19)\end{array}$ & $\begin{array}{l}0.0855 \\
(0.44)\end{array}$ \\
\hline lnpop & $\begin{array}{c}-0.8187^{* *} \\
(-2.55)\end{array}$ & $\begin{array}{c}-0.3459^{* * *} \\
(-2.78)\end{array}$ & $\begin{array}{l}-1.4285 \\
(-1.10)\end{array}$ & $\begin{array}{c}-1.1636^{* * *} \\
(-2.70)\end{array}$ & $\begin{array}{l}-2.8287 \\
(-1.07)\end{array}$ & $\begin{array}{l}-0.9936 \\
(-1.58)\end{array}$ & $\begin{array}{l}-0.0522 \\
(-0.39)\end{array}$ & $\begin{array}{l}-0.0748 \\
(-0.94)\end{array}$ \\
\hline lnagg & $\begin{array}{c}0.2384^{* * * *} \\
(6.96)\end{array}$ & $\begin{array}{c}0.0975^{* * * *} \\
(4.61)\end{array}$ & $\begin{array}{c}0.2408 * * * \\
(4.57)\end{array}$ & $\begin{array}{c}0.2038^{* * * *} \\
(4.96)\end{array}$ & $\begin{array}{c}0.2928 * * * \\
(3.63)\end{array}$ & $\begin{array}{c}0.1620^{* *} \\
(2.11)\end{array}$ & $\begin{array}{l}0.0082 \\
(0.33)\end{array}$ & $\begin{array}{l}-0.0020 \\
(-0.11)\end{array}$ \\
\hline $\mathrm{R}^{2}$ & 0.3860 & 0.3230 & 0.6081 & 0.5982 & 0.5100 & 0.4550 & 0.3147 & 0.3080 \\
\hline F & 18.23 & - & 18.23 & - & 7.15 & - & 3.85 & - \\
\hline
\end{tabular}

442

Note: $* * * * *$, and $*$ refer to the $1 \%, 5 \%$, and $10 \%$ significance levels, respectively; fe represents fixed effect model; re represents random effects model.

\section{Conclusions and policy suggestions}

\subsection{Conclusions}

This study put forward a theoretical framework for the impact of economic transformation on IEE based on the Super-efficiency DEA model to measure the IEE of the Yellow River basin from 2008 to 2017. The ESDA method was used to explore the spatial and temporal evolution of IEE, and the panel regression model was used to study the main driving factors of IEE. The main conclusions were as follows:

(1) From 2008 to 2017, the IEE of the Yellow River Basin showed an elongated S-shaped temporal evolution characteristic. During the study period, the regional differences of IEE of cities in the Yellow River Basin were significant. The IEE of the lower reaches was the highest, followed by the middle reaches, and the upper reaches were the lowest. The results of kernel density estimation indicate that the overall level of IEE in the Yellow River Basin is improving, but the gap between regions is widening.

(2) The IEE in the Yellow River Basin had significant global and local spatial autocorrelation, and 

is the low-value area.

(3) The influence factors of IEE in the Yellow River Basin showed spatial heterogeneity in their significant effect in the middle and upper reaches and the whole basin. Decentralization had a negative effect on the whole basin and the middle reaches, a positive effect on the upper reaches, and an insignificant effect on the lower reaches. Decentralization had a negative effect on the whole basin and the middle reaches, a positive effect on the upper reaches, and an insignificant effect on the lower reaches. In addition, industrial structure, economic development level, scientific and technological innovation, population agglomeration, industrial agglomeration also had different effects on the IEE of the Yellow

\subsection{Policy suggestions}

In view of the regional differences of IEE in the Yellow River Basin, different industrial

471 development policies and environmental control measures should be formulated according to local conditions. Based on the research conclusions, we make the suggestions that follow. (1) The lower reaches of the Yellow River Basin should make full use of the development opportunities brought by globalization and marketization, accelerate the adjustment of industrial structure, improve the market

475 system and mechanism, transform the model of industrial development, improve the efficiency of industrial production, and reduce energy consumption and pollution emission. (2) The middle reaches should adjust the industrial structure in a timely manner, reduce excessive dependence on coal and other resource-based industries, actively seek new driving forces for industrial development, strengthen 
exchanges and cooperation with the developed areas along the eastern coast, and promote the upgrading of regional industrial structure and high-quality economic development. (3) The ecological environment of the upper reaches is very fragile. The local government should give full play to the role of macrocontrol in the development of regional industries. On the basis of protecting the local ecological environment, it should selectively introduce advanced industries and technologies from the eastern developed regions, strengthen the industrial and technological exchanges with eastern developed regions, and promote ecological environment protection and high-quality development of the upper reaches.

\section{Declarations}

Availability of data and materials The datasets used and/or analysed during the current study are available from the corresponding author on reasonable request.

Ethics approval and consent to participate Not applicable.

Consent for publication Not applicable.

Competing interests The authors declare no competing interests.

Funding his study is supported by the National Science Foundation of China(Grant No. 41701177).

Author contribution All authors contributed to the study conception and design. Methodology, Software and Writing-Original draft preparation were performed by Chengzhen Song. Conceptualization, Methodology, Writing- Review \& Editing, and Funding Acquisition were performed by Guanwen Yin. Data curation and Software were performed by Zhilin Lu. Conceptualization, Writing-Review \& Editing, Methodology, Supervision, and Funding acquisition were performed by Yanbin Chen. All authors read and approved the final manuscript.

\section{References}

Andersen P, Petersen NC (1993): A Procedure for Ranking Units in Data Envelopment Analysis. Management Science 39, 1261-1264.

Bao J, Yang X, Zhao Z, Wang Z, Yu C, Li X (2015): The Spatial-Temporal Characteristics of Air Pollution in China from 2001-2014. Int J Environ Res Public Health 12, 15875-15887. DOI: https://doi.org/10.3390/ijerph121215029. 
Campos NF, Horváth R (2012): Reform redux: Measurement, determinants and growth implicati ons. European Journal of Political Economy 28, 227-237. DOI: https://doi.org/10.1016/j. ejpoleco.2011.12.002.

Charnes A, Cooper WW, Rhodes E (1979): Measuring the efficiency of decision-making units. European Journal of Operational Research 3, 339.

Chen F, Zhao T, Wang J (2019): The evaluation of energy-environmental efficiency of China's industrial sector: based on Super-SBM model. Clean Technologies and Environmental Policy 21, 1-18. DOI: https://doi.org/10.1007/s10098-019-01713-0.

Chen W, Si W, Chen ZM (2020): How technological innovations affect urban eco-efficiency in China: A prefecture-level panel data analysis. Journal of Cleaner Production 270, 122479. DOI: https://doi.org/10.1016/j.jclepro.2020.122479.

Chen X, Chang CP (2020): Fiscal decentralization, environmental regulation, and pollution: a s patial investigation. Environmental Science and Pollution Research 27. DOI: https://doi. org/10.1007/s11356-020-09522-5.

Chen Y, Yin G, Liu K (2021): Regional differences in the industrial water use efficiency of China: The spatial spillover effect and relevant factors. Resources, Conservation and Recycling 167, 105239. DOI: https://doi.org/10.1016/j.resconrec.2020.105239.

Cheng S, Fan W, Chen J, Meng F, Yang Z (2019): The impact of fiscal decentralization on $\mathrm{CO}_{2}$ emissions in China. Energy 192, 116685. DOI: https://doi.org/10.1016/j.energy.2019.116685.

Feng L (2014): Does Foreign Direct Investment Harm the Host Country's Environment? Evidence from China. Current Topics in Management.

Getis A, Ord JK (1992): The Analysis of Spatial Association by Use of Distance Statistics. Geographical Analysis 24.

Guan W, Xu S (2016): Study of spatial patterns and spatial effects of energy eco-efficiency in China. Journal of Geographical Sciences 26, 1362-1376. DOI: https://doi.org/10.1007/s1 1442-016-1332-X.

HA, Lin, TU, Jianjun, YANG, Jianping, XU, Chunhai, PANG, Jiaxing (2020): Regional eco-efficiency evaluation and spatial pattern analysis of the Yangtze River Economic Zone. Journal of Geographical Sciences v.30, 78-100. DOI: https://doi.org/10.1007/s11442-020-1773-0.

Hao Y, Gai Z, Yan G, Wu H, Irfan M (2021): The spatial spillover effect and nonlinear relati onship analysis between environmental decentralization, government corruption and air pollution: Evidence from China. Science of The Total Environment 763, 144183. DOI: https://doi.org/10.1016/j.scitotenv.2020.144183.

Haoran, Zhao, Sen, Guo, Huiru, Zhao (2019): Provincial energy efficiency of China quantified by three-stage data envelopment analysis. Energy. DOI: https://doi.org/10.1016/j.energy.2 018.10.063.

Huang Z, Wei YD, He C, Li H (2015): Urban land expansion under economic transition in C hina: A multi-level modeling analysis. Habitat International 47, 69-82. DOI: https://doi. org/10.1016/j.habitatint.2015.01.007.

J., Quariguasi, Frota, Neto, and, G., Walther, and, J., Bloemhof (2009): A methodology for ass essing eco-efficiency in logistics networks. European Journal of Operational Research. DOI: https://doi.org/10.1016/j.ejor.2007.06.056.

Jiang L, He S, Zhong Z, Zhou H, He L (2019): Revisiting environmental kuznets curve for carbon dioxide emissions: The role of trade. Structural change and economic dynamics 50, 245-257. DOI: 
https://doi.org/10.1016/j.strueco.2019.07.004.

Jiya AN, Sama MC, Ouedraogo I (2020): Infrastructure, trade openness and economic transformation in Common Market for Eastern and Southern Africa member countries. Social Sciences \& Humanities Open. DOI: https://doi.org/10.1016/j.ssaho.2020.100072.

Lan J, Kakinaka M, Huang X (2012): Foreign Direct Investment, Human Capital and Environ mental Pollution in China. Environmental and Resource Economics 51, 255-275. DOI: https://doi.org/10.1007/s10640-011-9498-2.

Lin B, Zhu J (2020): Chinese electricity demand and electricity consumption efficiency: Do the structural changes matter? Applied Energy 262, 114505. DOI: https://doi.org/10.1016/j. apenergy.2020.114505.

Liu L, Ding D, He J (2017a): Fiscal Decentralization, Economic Growth, and Haze Pollution Decoupling Effects: A Simple Model and Evidence from China. Computational Economics. DOI: https://doi.org/10.1007/s10614-017-9700-x.

Liu Q, Wang S, Li B, Zhang W (2020a): Dynamics, differences, influencing factors of eco-efficiency in China: A spatiotemporal perspective analysis. Journal of Environmental Management 264, 110442. DOI: https://doi.org/10.1016/j.jenvman.2020.110442.

Liu Y, Hao Y, Gao Y (2017b): The environmental consequences of domestic and foreign invest ment: Evidence from China. Energy Policy 108, 271-280. DOI: https://doi.org/10.1016/j. enpol.2017.05.055.

Liu Y, Li J, Yang Y (2018): Strategic adjustment of land use policy under the economic transformation. Land Use Policy 74, 5-14. DOI: https://doi.org/10.1016/j.landusepol.2017.07.005.

Liu Y, Zhu J, Li EY, Meng Z, Song Y (2020b): Environmental regulation, green technological innovation, and eco-efficiency: The case of Yangtze river economic belt in China. Tech nological Forecasting and Social Change 155, 119993. DOI: https://doi.org/10.1016/j.tec hfore.2020.119993.

Marques AC, Fuinhas JA, Tomas C (2019): Energy efficiency and sustainable growth in industrial sectors in European Union countries: A nonlinear ARDL approach. Journal of Cleaner Production 239, 118045.1-118045.12. DOI: https://doi.org/10.1016/j.jclepro.2019.118045.

Merlevede B (2003): Reform reversals and output growth in transition economies. Economics of Transition 11, 649-669. DOI: https://doi.org/10.1111/j.0967-0750.2003.00165.x.

Moran, P.A.P (1948): The interpretation of statistical maps. J. R. Stat. Soc. Ser B-Stat. Methodol 10, 243-251.

Mu R (2018): Bounded Rationality in the Developmental Trajectory of Environmental Target Policy in China, 1972-2016. Sustainability 10, 199. DOI: https://doi.org/10.3390/su10010199.

Pao H-T, Tsai C-M (2011): Multivariate Granger causality between $\mathrm{CO}_{2}$ emissions, energy consumption, FDI (foreign direct investment) and GDP (gross domestic product): Evidence from a panel of BRIC (Brazil, Russian Federation, India, and China) countries. Energy 36, 685-693. DOI: https://doi.org/10.1016/j.energy.2010.09.041.

Ren Y, Fang C, Li G (2020): Spatio-temporal characteristics and influential factors of eco-efficiency in Chinese prefecture-level cities: A spatial panel econometric analysis. Journal of Cleaner Production 260. DOI: https://doi.org/10.1016/j.jclepro.2020.120787.

Schaltegger S, Sturm A (1990): Ecological rationality: approaches to design of ecology-oriented management instruments. Die Unternehm 44, 273-290.

Shah IH, Dong L, Park HS (2020): Tracking urban sustainability transition: An eco-efficiency analysis 
on eco-industrial development in Ulsan, Korea. Journal of Cleaner Production 262, 121286. DOI: https://doi.org/10.1016/j.jclepro.2020.121286.

Shen N, Peng H (2020): Can industrial agglomeration achieve the emission-reduction effect? SocioEconomic Planning Sciences, 100867. DOI: https://doi.org/10.1016/j.seps.2020.100867.

Tong Y, Zhou H, Jiang L (2020): Exploring the transition effects of foreign direct investment on the ecoefficiency of Chinese cities: Based on multi-source data and panel smooth transition regression models. Ecological Indicators. DOI: https://doi.org/10.1016/j.ecolind.2020.107073.

Wang DT, Chen WY (2014): Foreign direct investment, institutional development, and environmental externalities: Evidence from China. Journal of Environmental Management 135, 81-90. DOI: https://doi.org/10.1016/j.jenvman.2014.01.013.

Wang L, Zhang F, Fu W, Tan Q, Chen J (2020): Analysis of temporal and spatial differences and influencing factors of energy eco-efficiency in energy-rich area of the Yellow River Basin. Physics and Chemistry of the Earth. DOI: https://doi.org/10.1016/j.pce.2020.102976.

Wang S, Zhou C, Li G, Feng K (2016): $\mathrm{CO}_{2}$, economic growth, and energy consumption in China's provinces: Investigating the spatiotemporal and econometric characteristics of $\mathrm{C}$ hina's $\mathrm{CO}_{2}$ emissions. Ecological Indicators 69, 184-195. DOI: https://doi.org/10.1016/j.e colind.2016.04.022.

Wang Z, Liu B, Wang L, Shao Q (2021): Measurement and Temporal \& Spatial Variation of Urban ecoefficiency in the Yellow River Basin. Physics and Chemistry of the Earth Parts A/B/C, 102981. DOI: https://doi.org/10.1016/j.pce.2021.102981.

Wencong Y, Yanpeng C, Zhifeng Y, Qiangqiang R, Zhi D (2018): Structural optimization for i ndustrial sectors to achieve the targets of energy intensity mitigation in the urban clust er of the Pearl River Delta. Ecological Indicators 95, 673-686. DOI: https://doi.org/10.1 016/j.ecolind.2018.08.009.

Wu J, Zhu Q, Chu J, Liang L (2015): Two-Stage Network Structures with Undesirable Intermediate Outputs Reused: A DEA Based Approach. Computational Economics 46, 455-477. DOI: https://doi.org/10.1007/s10614-015-9498-3.

Yang Y, Tang D, Zhang P (2020): Effects of fiscal decentralization on carbon emissions in China. International Journal of Energy Sector Management 14, 213-228.

Yi J, Chen Y, Wang C, Kafouros M (2015): Spillover Effects of Foreign Direct Investment: H ow do Region-Specific Institutions Matter? Management International Review 55, 539-5 61. DOI: https://doi.org/10.1007/s11575-014-0235-2.

Yin G, Liu Y, Wang F (2018): Emerging Chinese new towns: Local government-directed capita 1 switching in inland China. Cities 79, 102-112. DOI: https://doi.org/10.1016/j.cities.201 8.02.026.

Yu C, Li H, Jia X, Li Q (2015): Improving resource utilization efficiency in China's mineral resourcebased cities: A case study of Chengde, Hebei province. Resources, Conservation and Recycling 94, 1-10. DOI: https://doi.org/10.1016/j.resconrec.2014.10.013.

Yu Y, Huang J, Zhang N (2018): Industrial eco-efficiency, regional disparity, and spatial conver gence of China's regions. Journal of Cleaner Production 204, 872-887. DOI: https://doi. org/10.1016/j.jclepro.2018.09.054.

Zhang B, Bi J, Fan Z, Yuan Z, Ge J (2008): Eco-efficiency analysis of industrial system in C hina: A data envelopment analysis approach. Ecological Economics 68, 306-316. DOI: https://doi.org/10.1016/j.ecolecon.2008.03.009. 
Zhang B, Miao C (2020): The evolution and driving forces of the spatial-temporal pattern of land use in the Yellow River Basin. Resources Science 42, 460-473.(in Chinese)

Zhang J, Liu Y, Chang Y, Zhang L (2017a): Industrial eco-efficiency in China: A provincial quantification using three-stage data envelopment analysis. Journal of Cleaner Production 143, 238-249. DOI: https://doi.org/10.1016/j.jclepro.2016.12.123.

Zhang K, Zhang ZY, Liang QM (2017b): An empirical analysis of the green paradox in China: From the perspective of fiscal decentralization. Energy Policy 103, 203-211. DOI: htt ps://doi.org/10.1016/j.enpol.2017.01.023.

Zhao, Changhong, Zhang, Haonan, Zeng, Yurong, Li, Fengyun, Liu, Yuanxin (2018): Total-Factor Energy Efficiency in BRI Countries: An Estimation Based on Three-Stage DEA Model. Sustainability. DOI: https://doi.org/10.3390/su10010278.

Zhiqing L, Yong G, Hancheng D, Jeffrey W, Yang X, Rui W, Wei Y, Zhongjue Y (2018): Regional impacts of launching national carbon emissions trading market: A case study of Shanghai. Applied Energy 230, 232-240. DOI: https://doi.org/10.1016/j.apenergy.2018.08.117.

Zhou C, Shi C, Wang S, Zhang G (2018): Estimation of eco-efficiency and its influencing factors in Guangdong province based on Super-SBM and panel regression models. Ecological Indicators 86, 67-80. DOI: https://doi.org/10.1016/j.ecolind.2017.12.011.

Zhou Y, Kong Y, Sha J, Wang H (2019): The role of industrial structure upgrades in eco-efficiency evolution: Spatial correlation and spillover effects. Science of the Total Environment 687. DOI: https://doi.org/10.1016/j.scitotenv.2019.06.182.

Zhou Y, Liu Z, Liu S, Chen M, Zhang X, Wang Y (2020): Analysis of industrial eco-efficiency and its influencing factors in China. Clean Technologies and Environmental Policy 22, 2023-2038. DOI: https://doi.org/10.1007/s10098-020-01943-7. 